\title{
Kadınlarda Bazal Metabolizma Hızının Bazı Vücut Kompozisyonları İle
}

\section{Karşılaştırılması}

\author{
Hacı Bayram TEMÜR ${ }^{1 *}$ (D) Ramazan CEYLAN ${ }^{2}$ (D) \\ ${ }^{1}$ Bayburt Üniversitesi, Beden Eğitimi ve Spor Yüksekokulu, BAYBURT
}

DOI: 10.31680/gaunjss.765954

Orijinal Makale / OriginalArticle

Geliş Tarihi / Received:07.07.2020

Kabul Tarihi / Accepted: 05.10.2020

Yayın Tarihi / Published: 14.12.2020

Öz

Bu çalışmayla, sedanter yaşam tarzına sahip kadınların, bazı vücut kompozisyonlarından yaş, boy, vücut ağırlığı, Beden Kitle İndeksi (BKi), bel çevresi, bel-kalça oranının (B/K) birbirleri ile ve bazal metabolizma hızları (BMH) ile karşılaştıııması amaçlandı. Yaşları ortalaması, 34,57 $\pm 10,01$ yıl, vücut ağırıkları ortalaması 69,66 $\pm 12,92 \mathrm{~kg}$ olan ve sedanter bir yaşam süren 173 kadın gönülülük esasına göre çalışmaya dahil edildi. Katııımcıların, yaş, boy uzunluğu, vücut ağırlığı, bel ve kalça çevresi ölçümleri yapıldı. Bu ölçümlerden yararlanılarak bel-kalça oranları ve BKI değerleri hesaplandı. Ayrıca kadınlar sabah aç iken BMH belirlendi. Bu verilerin istatistik analizlerinde, SPSS 21 paket programı kullanıldı. Sonuçta, katııımcıların \% 76,3 nün bel-kalça oranları kadınlarda üst sınır olarak kabul gören, 0,80 ' in üzerinde olduğu belirlendi. Ayrıca, yaş değişkeninin, boy değişkeni ile negatif yönlü korelasyon gösterdiği tespit edildi. Diğer taraftan, vücut ağırlığı, BKi, bel çevresi ve bel-kalça oranı değişkenleri ile ise pozitif yönlü korelasyon gösterdiği belirlendi. Boy değişkenin, BMH ile pozitif yönlü, geriye kalan yaş, BKi, bel çevresi ve bel-kalça oranı ile negatif yönlü korelasyon gösterdiği saptandı. Vücut ağırlığının, BKİ, bel çevresi, BMH ve bal-kalça oranı ile pozitif yönlü korelasyon gösterdiği anlaşıldı. Bunlarla birlikte, BKI değerlerinin, bel çevresi ile pozitif korelasyon gösterdiği belirlendi. Ayrıca bel çevresi değişkeninin, bel-kalça oranı ile pozitif yönlü korelasyon gösterdiği saptandı. Sonuçta, çalışılan vücut kompozisyonlarından yaş değişkeninin BMH ile anlamlı olmasa da negatif yönlü, boy uzunluğu ve vücut ağırlığının ise pozitif yönlü anlamlı bir ilişki içerisinde olduğu söylenebilir.

Anahtar Kelimeler: Kadın, BMH, Vücut Ağırıı̆ı, Bel-kalça, BKI

\section{Comparison of Basal Metabolic Rate in Women with Some Body Compositions}

\begin{abstract}
In this study, it was aimed to compare some body compositions of women with a sedentary lifestyle, including age, height, body weight, Body Mass Index (BMI), waist circumference, waist-hip ratio (B / C) with each other and their basal metabolic rate (BMR). 173 women with a mean age of $34.57 \pm 10.01$ years, a mean body weight of $69.66 \pm 12.92 \mathrm{~kg}$ and a sedentary life were included in the study on a voluntary basis. Age, height, body weight, waist and hip circumference of the participants were measured. Using these measurements, waist-hip ratios and $\mathrm{BMI}$ values were calculated. In addition, $\mathrm{BMH}$ was determined when women were hungry in the morning. SPSS 21 package program was used for statistical analysis of these data. As a result, it was determined that $76.3 \%$ of the participants had waist-hip ratios above 0.80 , which is accepted as the upper limit for women. In addition, it was found that the age variable had a negative correlation with the height variable. On the other hand, it was determined that there was a positive correlation with the variables of body weight, BMI, waist circumference and waist-hip ratio. Height variable was found to be positively correlated with BMR, and negatively correlated with remaining age, BMI, waist circumference and waist-hip ratio. It was found that there was a positive correlation between body weight, BMI, waist circumference, BMR and honey-hip ratio. In addition, it was determined that BMI values were positively correlated with waist circumference. In addition, the waist circumference variable was found to have a positive correlation with the waist-to-hip ratio. In conclusion, it can be said that the age variable, which is one of the body compositions studied, is in a negative direction, although not significant, and that height and body weight have a positive significant relationship.
\end{abstract}

Keywords: Women, BMH, Waist circumference, Waist / Hip, BMI

\footnotetext{
* Sorumlu yazar: H. Bayram TEMUR
} 


\section{Giriş}

Vücut kompozisyonları, bireyin sağlığının değerlendirilmesinde gönümüzde sıkça başvurulan yöntemlerden biri haline gelmiştir. Vücut kompozisyonları aynı zamanda kişinin spor dallarına yönlendirilmede de göz önüne alınan önemli bir faktör olarak dikkate alınmaktadır.

Antropometri, vücut kompozisyonunu, boyutunu ve oranlarını değerlendirmek için en ucuz, invaziv olmayan ve evrensel olarak uygulanabilir tek yöntemdir (WHO, 2005). En sık kullanılan antropometrik ölçümler; BKI, üst kol çevresi, bel/kalça oranı, baldır çevresi ve deri kıvrım kalınlığı (triseps, biseps, subscapular, suprailiak) dır (Yosmaoğlu ve ark.,,2010). Antropometrik ölçümler, yalnız bireyin değil, toplumun beslenme durumunun değerlendirilmesinde de en sık kullanılan yöntemlerdir (Neyzi ve ark., 2008). BKI tanı koyma amaçıı olmayıp etkili bir tarama aracıdır (CDC, 2008).

Karın çevresindeki yağ birikimi kalçalara ve vücudun diğer bölgelerine göre daha sık görülür ve daha büyük sağlık riskleri oluşturur (Bei-Fan,2002; Ashwell, 1994). Bel çevresi en iyi karın bölgesi, iç organlar ve deri altı yağ birikiminin yanı sıra karın kas tonusunu da yansıtır (Sharma, 2003; Valsamakis ve ark., 2004) ve genel sağlığı değerlendirirken göz önünde bulundurulması gereken kriterlerden biridir (Lahti-Koski, 2002).

Bel-kalça oranı, sağığın ve ciddi sağlık sorunlarının oluşma riskinin bir göstergesi veya ölçüsü olarak kullanılmıştır. Kadınlarda $B / K$ oranı doğurganlık ile ilişkilidir. Araştırmalar, "elma tipi" beden (bel çevresinde daha fazla ağırık) yapısına sahip kişilerin "armut tipi" beden (kalça çevresinde daha fazla ağırlık) yapısına sahip olanlardan daha fazla sağlık riski ile karşı karşıya olduğunu göstermektedir. Ulusal Diyabet, Sindirim ve Böbrek Hastalıkları Enstitüsü (NIDDK), bel-kalça oranları 0.8 'den fazla olan kadınların ve 1.0'dan fazla olan erkeklerin yağ dağılımı nedeniyle sağlık riskinin arttığını belirtmektedir (wikipedi.com).

Bel-kalça oranının, bel çevresi ve vücut kitle indeksinden daha iyi bir kardiyovasküler hastalık yordayıcısı olduğu gösterilmiştir (Mørkedalve ark., 2011). Bununla birlikte, bazı çalışmalar, kardiyovasküler risk faktörleri (Dobbelsteynve ark., 2001), vücut yağ dağı̆ımı (Ketel ve ark., 2007) ve tip 2 diyabette hipertansiyonun iyi bir göstergesi (Picon ve ark.,2007) olarak bel-kalça oranını değil bel çevresini göstermişlerdir.

Vücuttaki toplam yağ miktarı önemli olmakla beraber, yağın nerede biriktiğini bilmek daha önemlidir. Karın çevresinde yağ birikimi, kalça ve vücudun diğer 
bölgelerinde yağ birikiminden, daha sık görülmekte ve daha fazla sağlık risklerine neden olmaktadır (Himas-Hagen, 1997).

Noyan (2010), bazal metabolizmayı, vücuda alınan besin öğelerinin parçalanarak bunlardan enerji elde edilmesi (katabolizma) ve yeni maddelerin biyosentezini (anabolizma) içeren fiziksel ve kimyasal olaylarının tümü olarak tanımlamıştır. Koivisko (2009), ise bazal metabolizma hızını, vücudu korumak için dinlenik halde iken hücrelerin harcadığı enerji olarak tanımlamıştır. Noyan (2010), 1218 saat süresince besin almamış, tam istirahat halinde ve ısısı değişken olmayan bir ortamda bir şahsın harcadığı enerji metabolik hız olarak tanımlamıştır. Bazal durumda meydana gelen enerjinin bir kısmı tam istirahat halindeki vücudun gerekli fonksiyonlarının yerine getirilmesi için harcanır. Diğer kısmı ısı haline çevrilir (Noyan, 2010). BMH, günlük harcanan toplam enerjinin yaklaşık \% 60-70'ini oluşturur (Koivisko, 2009). Bunun \%29'unu karaciğer, \%19'unu beyin, \%18'ini iskelet kasları harcar (Pekcan, 2008). Geriye kalan enerjinin yüzde 10-15'lik bölümü almış olduğumuz gıdaların emilimi sırasında harcanır. Bu enerji mide ve bağırsak hücreleri tarafından harcanır. Kalan yüzde 15-30'luk bölümüyse gün içinde bize hareketlilik sağlayan çizgili kaslar tarafından harcanır (MEB, 2011).

$\mathrm{Bu}$ çalışmayla, sedanter yaşam süren kadınların, bazı vücut kompozisyonlarının birbirleri ile ve bazal metabolizma hızları ile karşılaştıııması amaçlandı.

\section{Yöntem}

Çalışma grubu: Çalışma grubunu, yaşları ortalaması $34,57 \pm 10,01$ yıl olan, Van ilinde sedanter bir yaşam tarzı süren ve gönüllülük esasına göre çalışmaya dahil

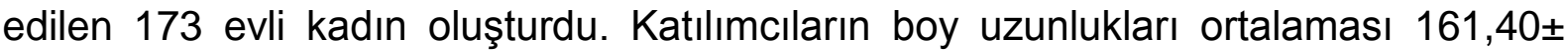
$6,12 \mathrm{~cm}$, vücut ağırlıkları ortalaması $69,66 \pm 12,92 \mathrm{~kg}$ ve BKI değerleri ortalaması ise $27,11 \pm 5,65 \mathrm{~kg} / \mathrm{m}^{2} \mathrm{dir}$.

Çalışma Parametreleri ve ölçüm yöntemi: Katılımcıların, yaş, boy uzunluğu, vücut ağırlığı, bel ve kalça çevresi ölçümleri yapıldı. Bu ölçümlerden yararlanılarak, deneklere ait bel-kalça oranları ve BKİ değerleri hesaplandı. Ayrıca kadınlar sabah aç iken $\mathrm{BMH}$ belirlendi.

Boy uzunluğu: Boy uzunluğu ölçümü düz bir zeminde katıııcı çıplak ayaklı iken metre kullanılarak ölçüldü.

Vücut ağırlığı: Vücut ağırlığı ölçümü katılımcı çıplak ayaklı iken hassas elektironik kantar ile ölçüldü. 
Bel çevresi: Bel çevresi, en alt kosta ile prosessus spina ilaca anterior superior arasındaki en küçük bel çevresi, göbek üzerinden yere paralel transfers mezru ölçülerek kaydedildi.

Kalça çevresi: Kişinin üzerinde en az giysi olduğu durumda iken yandan en geniş noktadan, esnemeyen mezura kullanılarak çevre ölçümü yapıldı.

BMH: BMH değerleri Kore yapımı, Jawon AVIS 333 PLUS marka Bioelectrical Impedance Analysis (BIA) cihazı ile belirlendi. Çalışmaya dahil edilenlerden, son 12 saat içinde gıda almamaları ve son 24 saat içinde sportif aktivitede bulunmamaları istendi. Ölçümler 5 dakikalık dinlenme sonrası oda sıcaklığında yapıldı.

\section{Verilerin analizi}

Elde edilen veriler, bilgisayar ortamına aktarıldı. Bu verilerin istatistik analizlerini yapmak için SPSS 21 paket programında, Correlations, Descrıptives ve Crosstabs analizleri kullanıldı.

Tablo 1. Katıımcılara ait tanımlayıcı bilgiler

\begin{tabular}{lccc}
\hline Değişkenler & $\mathrm{N}$ & Ortalama & Standart sapma \\
\hline Yaş (yıl) & 173 & 34,57 & 10,01 \\
\hline Boy uzunluğu $(\mathrm{cm})$ & 173 & 161,40 & 6,12 \\
\hline Vücut ağırlığı $(\mathrm{kg})$ & 173 & 69,66 & 12,92 \\
\hline BKI $\left(\mathrm{kg} / \mathrm{m}^{2}\right)$ & 173 & 27,11 & 5,65 \\
\hline
\end{tabular}

\section{Bulgular}

Tablo 2. Katılımcıların Bel/ Kalça oranlarına göre dağılımı

\begin{tabular}{lcc}
\hline Bel / Kalça & $\mathrm{N}$ & $\%$ \\
\hline$<0,80$ & 41 & 23,7 \\
\hline$>0,80$ & 132 & 76,3 \\
\hline
\end{tabular}

Tablo 2, Bel / Kalça oranları açısından incelendiğinde, katıımcıların \% 23, 7 sinin Bel/Kalça oranının 0,80'in altında olduğu, buna karşın $\% 76,3$ nün ise 0,80 'in üzerinde olduğu görüldü.

Tablo 3. Katııımcıların BKi değerlerine göre dağılımları

\begin{tabular}{lcc}
\hline BKi sınıfları (kg/m²) & $\mathrm{N}$ & $\%$ \\
\hline$<18,49($ Zayıf) & 2 & 1,2 \\
\hline $18,50-24,99($ Normal) & 68 & 39,3 \\
\hline $25-29,99$ (Fazla kilolu) & 55 & 31,8 \\
\hline$>30($ Obez) & 48 & 27,7 \\
\hline Toplam & 173 & 100 \\
\hline
\end{tabular}


Tablo 3 BKI değerlerine göre incelendiğinde, çalışmaya dahil edilen katıımcıların \% 1,2' sinin zayıf, \%39,3'ünün normal vücut ağırlığına sahip olduğu görüldü. Yine bunların \%31,8'inin fazla kilolu, \%27,7'sinin ise obez olduğu saptandı.

Tablo 4. Katıımcılara ait bazı değişkenlerin birbirleri ile olan korelasyon tablosu

\begin{tabular}{|c|c|c|c|c|c|c|c|c|}
\hline Yaş (yıl) & $\begin{array}{l}\text { Korelas. katsayısı } \\
\mathrm{P} \\
\end{array}$ & 1 & & & & & & \\
\hline $\begin{array}{l}\text { Boy uzun } \\
\text { luğu }(\mathrm{cm})\end{array}$ & $\begin{array}{l}\text { Korelas. katsayısı } \\
P\end{array}$ &,- 411 & 1 & & & & & \\
\hline \multirow{2}{*}{$\begin{array}{l}\text { Vücut } \\
\text { ağırlığı }(\mathrm{kg})\end{array}$} & Korelas. katsayısı & , 390 &,- 095 & & & & & \\
\hline & $\begin{array}{l}\text { P } \\
\text { Korelas. katsayısı }\end{array}$ & $\begin{array}{l}, 000 \\
, 331\end{array}$ & $\begin{array}{l}, 214 \\
-, 287\end{array}$ & $\begin{array}{c}1 \\
, 503\end{array}$ & \multirow[b]{2}{*}{1} & & & \\
\hline $\mathrm{BKI}\left(\mathrm{kg} / \mathrm{m}^{2}\right)$ & $\mathrm{P}$ &, 000 &, 000 &, 000 & & & & \\
\hline $\begin{array}{l}\text { Bel çevresi } \\
(\mathrm{cm})\end{array}$ & $\begin{array}{l}\text { Korelas. katsayısı } \\
\mathrm{P}\end{array}$ & $\begin{array}{l}., 525 \\
, 000\end{array}$ & $\begin{array}{l}-, 297 \\
, 000\end{array}$ & $\begin{array}{l}, 775 \\
, 000\end{array}$ & $\begin{array}{l}, 413 \\
, 000\end{array}$ & 1 & & \\
\hline \multirow{2}{*}{$\begin{array}{l}\text { BMH } \\
\text { (kkal/gün) }\end{array}$} & Korelas. katsayısı &,- 114 & ,229 & 170 & ,086 & ,107 & \multirow{2}{*}{1} & \\
\hline & $\mathrm{P}$ & ,134 & ,002 & ,025 & ,258 & 161 & & \\
\hline \multirow{3}{*}{$\begin{array}{l}\text { Bel/ Kalça } \\
(\mathrm{cm})\end{array}$} & Korelas. katsayısı & ,352 &,- 163 & ,238 & 120 & 686 & ,046 & \\
\hline & $P$ & ,000 & ,032 & ,002 & ,116 & ,000 & 551 & 1 \\
\hline & & $\begin{array}{l}\text { Yaş } \\
(\mathrm{yll})\end{array}$ & $\begin{array}{l}\text { Boy } \\
\text { uzunluğu }\end{array}$ & $\begin{array}{l}\text { Vücut } \\
\text { ağırlığı }\end{array}$ & BKI & \begin{tabular}{l|} 
Bel \\
Çevresi
\end{tabular} & $\mathrm{BMH}$ & Bel/Kalça \\
\hline
\end{tabular}

Tablo 4 incelendiğinde, yaş değişkeninin, boy değişkeni ve BMH ile negatif yönlü bir korelasyon gösterdiği tespit edildi. Bu korelasyon katsayıları ve anlamlılık düzeyleri sırasıyla ( $r=-, 411 ; p=0,00),(r=-, 114 ; p=, 132)$ şeklindedir. Yaş değişkeni diğer taraftan, vücut ağırlığı $(r=, 390 ; p=, 000)$, BKi $(r=, 331 ; p=, 000)$, Bel çevresi $(r=, 525$; $p=, 000)$ ve Bel/ kalça $(r=, 352 ; p=, 000)$ değişkenleri ile pozitif yönlü korelasyon gösterdiği belirlendi. Boy değişkenine bakıldığında ise sadece BMH ( $r=, 229 ; p=, 002)$ ile pozitif yönlü, geriye kalan yaş ( $r=-, 411 ; p=, 000)$, vücut ağırlığı $(r=-, 095 ; p=, 214)$, BKI $(r=-, 287 ; p=, 000)$, Bel çevresi $(r=-, 297 ; p=, 000)$ ve Bel / Kalça oranı $(r=-, 163$; $p=, 032)$ ile negatif yönlü korelasyon gösterdiği ortaya kondu. Vücut ağırlığının, BKi $(r=, 503 ; p=, 000)$, bel çevresi $(r=, 775 ; p=, 000), B M H(r=, 170 ; p=, 025)$ ve bal/kalça oranı $(r=, 238 ; p=, 002)$ ile pozitif yönlü korelasyon gösterdiği anlaşıldı. Yine BKi değerlerinin, bel çevresi $(r=, 413 ; p=, 000)$, BMH $(r=, 086 ; p=, 258)$ ve bel/kalça oranı $(r=, 120 ; p=, 116)$ ile pozitif korelasyon gösterdiği belirlendi. Ayrıca bel çevresi değişkeninin, BMH $(r=, 107 ; p=, 161)$ ve bel/kalça oranı $(r=, 686 ; p=, 000)$ ile pozitif yönlü korelasyon gösterdiği saptandı. Son olarak BMH nın, bel/kalça oranı ( $r=, 046$; $p=, 551)$ değişkeni ile pozitif korelasyon gösterdiği tespit edildi. 


\section{Tartışma ve Sonuç}

Katılımcıların bel - kalça oranları incelendiğinde, \% 23, 7 sinin Bel- kalça oranının 0,80'in altında olduğu, bunun la birlikte \% 76,3 nün ise 0,80'in üzerinde olduğu görüldü. Pekcan (2008), bel-kalça oranının android ve jineoid tip şişmanlığın tanımlanmasında kullanıldığını ifade etmiştir. İlhan - Akalın ve Değirmenci (2004), 30 yaş üzeri popülâsyonda BKI ve bel-kalça oranını ve kronik hastalıklarla ilişkisini inceledikleri çalışmada, kadınlarda bel-kalça oranının $>80 \mathrm{~cm}$ 'nin üzerine olmasını yüksek olarak kabul etmişlerdir. Yine kadınların \% 48,1'nin yüksek bel-kalça oranına sahip olduğunu ifade etmişlerdir. Bel-kalça oranı yüksek olan bireylerin diyabet risk dağılımı \% 17,5, hipertansiyon risk dağılımı \% 41,4 ve koroner arter hastalığı risk dağılımının ise \% 13,8 olduğunu bildirmişlerdir.

Çalışmaya dahil edilen kadınların BKİ değerleri göz önüne alındığında, sadece \%1'inin zayıf ve \%39,3'ünün ise normal sayılabilecek BKİ değerine sahip olduğu görüldü. Ayrıca BKİ açısından fazla kilolu sınıfına girenler $(\% 32,8)$ ile obez sınıfına girenlerin $(\% 27,7)$ toplam oranının \% 59,5 gibi büyük bir yüzdeyi oluşturduğu saptandı. Üstelik bu yüksek yüzde, yaşları ortalamasının $(34,57 \pm 10,01$ yıl) bakımından genç olan grupta olması daha da manidardır. Yardımcı ve Özfer Özçelik 2006 yılında yaptıkları çalışmada, Beden kitle indeksi değerlerine göre kadınların \% 26,3 'ü normal $\left(B K I=20,0-24,9 \mathrm{~kg} / \mathrm{m}^{2}\right), \%$ 30,5'i fazla kilolu $\left(B K I=25,0-29,9 \mathrm{~kg} / \mathrm{m}^{2}\right)$ ve $\% 38,9^{\prime} u$ şişman (BKî= $>30 \mathrm{~kg} / \mathrm{m}^{2}$ ) olduğunu ifade etmişlerdir. Nazlıcan ve ark.,

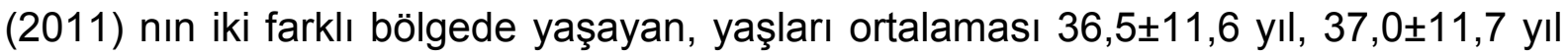
olan kadınlarda üzerinde yaptıkları çalışmada, BKI değerlerine göre \% 1,3'ünün "zayıf”, \%32,3'ünün "normal kilolu” \% 38,1'inin "fazla kilolu”, \% 28,3'ünün ise "obez olduğunu tespit etmişlerdir. Türk yetişkinlerinde yapılan TEKHARF çalışmasında, ülkemizdeki obezite yaygınlığı; 1990 yılında kadınlarda \% 32 iken, bu oranın 2001/2002 yıllarında \% 44,2 olduğu bildirilmiştir (Sansoy, 2001). Literatür, çalışma bulgularını destekler mahiyettedir.

Çalışmadaki BKI değerlerinin, diğer değişkenlerle istatistiksel karşılaştırılması sonucu, bel çevresi $(r=, 413 ; p=, 000)$ ile pozitif yönlü anlamlı korelasyona sahipken, BMH $(r=, 086 ; p=, 258)$ ve bel-kalça oranı $(r=, 120 ; p=, 116)$ ile pozitif yönlü fakat anlamlı $(p<0,05)$ olmayan bir korelasyona sahip olmadığı tespit edildi. Yapılan bir çalışmada Yardımcı, Özfer Özçelik, 2006). BKI' nin bel çevresi ve bel-kalça oranı ile $p<0,01$ düzeyinde pozitif korelasyon gösterdiği rapor edilmiştir.

Katılımcılara ait yaş değişkeni dikkate alındığında, boy uzunluğu değişkeni ile negatif yönlü anlamlı korelasyon ( $r=-, 411 ; p=, 000)$ gösterdiği saptandı. Yine BMH ile 
de anlamlı olmasa da negatif yönlü korelasyon ( $r=-, 114 ; p=, 134)$ gösterdiği belirlendi. Bu bulgulara karşın yaş değişkeni, vücut ağırlığı $(r=, 390 ; p=, 000)$, BKI $(r=, 331 ; p=, 000)$, bel çevresi $(r=, 525 ; p=, 000)$ ve bel-kalça oranı $(r=, 352 ; p=, 000)$ ile pozitif yönlü anlamlı korelasyon katsayısına sahip olduğu ortaya kondu. Kadınlar üzerinde yapılan çalışmada (Yardımcı ve Özçelik 2006), yaş ile BKİ, bel çevresi, belkalça oranı ile pozitif yönlü korelasyon olduğunu belirtmişlerdir. Keskin (1993), beden kitle indeksi (BKi) ile hematolojik parametreler arasındaki ilişkiyi incelemek amacıyla, 120 kadını üzerinde yaptığı araştırmada yaş arttıkça BKİnin de arttığını ortaya koymuştur. Roubenoff ve Wilson (1993)'un yaptığı çalışmada, yaşla birlikte yağsız doku ve boy uzunluğunda azalma olduğunu bulmuşlardır. Yaşla birlikte kişinin kas ve kemik kütlesinde azalmalara bağlı olarak, boy uzunluğunda düşüş olur. Yine yaşla birlikte $\mathrm{BMH}$ ile birlikte fiziksel aktivite düzeyindeki azalma vücut yağ oranının artmasına neden olabilmektedir.

Yapılan analiz sonucunda, boy uzunluğu değişkeninin, vücut ağırlığı ile ( $r=$ ,095; $p=, 214)$ anlamlı olmayan, BKI ( $r=-, 287 ; p=, 000)$, bel çevresi $(r=-, 297 ; p=, 000)$ ve bel-kalça oranı ( $r=-, 163 ; p=, 032)$ ile ise anlamlı negatif yönlü korelasyon gösterdiği görüldü. Boy uzunluğunun çalışılan değişkenlerden sadece BMH ( $r=, 229 ; p=, 002)$ ile pozitif yönlü korelasyon gösterdiği saptandı. Temur (2018), 8-13 yaş arası 98 çocuk üzerinde yaptığı çalışmada, boy uzunluğunun BMH artırdığının ortaya koymuştur. Göçer (2016), vücut ağırlığı ve vücut kompozisyonunu (yağ ve kas miktarı) BMH'nı etkileyen faktörler arasında göstermiştir. Kleiber (1975) ise BMH değerini vücut yüzey alanı birimi başına kalori olarak ifade etmiştir. Burada boy uzunluğu, vücut yüzey alanını artırarak, BMH olumlu yönde etkilediği düşünülmektedir.

Deneklerin vücut ağılık değerlerinin diğer değişkenlerle ilişkisi incelendiğinde, BKI ( $r=, 503 ; p=, 000)$, Bel çevresi $(r=, 775 ; p=, 000)$, BMH $(r=, 170 ; p=, 025)$ ve bel kaça oranı $(r=, 238 ; p=, 002)$ ile pozitif yönlü anlamlı korelasyon içerdiği ortaya konuldu. Yapılan bir çalışmada (Yardımcı, Özfer Özçelik, 2006), vücut ağırlığının BKİ ve bel çevre uzunluğu ile pozitif yönlü bir korelasyon gösterdiği, bel - kalça oranı ile ise pozitif yönlü fakat anlamlı olmayan bir korelasyon gösterdiği ifade edilmiştir.

Katılımcılara ait bel çevre ölçüm değerlerinin, BMH $(r=, 107 ; p=, 161)$ anlamlı olmayan, bel-kalça oranı $(r=, 686 ; p=, 000)$ ile ise anlamlı korelasyon katsayısına sahip olduğu görüldü. Pekcan (2000) yaptığı çalışmayla, bel çevresinin bel-kalça oranı ile uygun bir korelasyon gösterdiğini. Bu yüzden de abdominal yağ kitlesi ve total vücut yağının bir göstergesi olduğunu ifade etmiştir. Lofgren ve ark., (2004) ise Bel çevresinin, BKI 'ye göre koroner kalp hastalıklarının riskini belirlemede daha 
güçlü bir ilişki gösterge olduğunu bildirmişlerdir. Çalışmada, bel-kalça oranı ölçüm değerlerinin, $\mathrm{BMH}(r=, 046 ; p=, 551)$ ile anlamlı $(p<0,05)$ bir korelasyon göstermediği elde edilen bir başka bulgudur.

\section{Kaynaklar}

Ashwell, M. (1994). Obesity İn Men and Women. Int J Obes Relat Metab Disord.18 Suppl. 1:s1-7

Bei-Fan, Z. (2002). Predictive Values of Body Mass İndex and Waist Circumference forRisk Factors of Certain Related Diseases in Chinese Adults: Study on Optimal Cut-Off Points of Body Mass İndex and Waist Circumference In Chinese Adults. Asia Pac J Clin Nutr. 11 Suppl 8:S685-93

Centers for Disease Control and Prevention (CDC). About child \& teen BMl; 2008. http://www.cdc.gov/healthyweight/assessing/bmi/childrens_bmi/about_children s_bmi.htm. Erişim Tarihi: 05.005.2020

Dobbelsteyn, C.J., Joffres, M.R., MacLean, D.R., Flowerdew, G. ( 2001). "A comparative evaluation of waist circumference, waist-to-hip ratio and body mass index as indicators of cardiovascular risk factors. The Canadian Heart Health Surveys". Int. J. Obes. Relat. Metab. Disord. 25 (5): 652-61.

Göçer, S. (2020).“Metabolizma hızı ölçümü” http://www.drserangocer.com Imetabolizma-hizi- Olçumu Erişim tarihi, 06.05.2020.

Himas-Hagen, J. (1997). Technical comments: On Raising energy expenditure in Ob/Obmice. Science; 276:1132-33.

İlhan -Akalın, S. ve Değirmenci, H. (2004). Kentsel bir bölgede beden kitle indeksi ve bel-kalça oranları yüksekliği sorunlarının sıklığı ve kronik hastalıklar ile ilişkileri; http: // www. dicle. edu.tr /- halks/ m. 141. htm. Erişim Tarihi: 08.06.2004.

Keskin, G. (1993). Beden kitle indeksi ile hematolojik parametreler arasındaki ilişki üzerine bir araştırma. Bilim uzmanlığı tezi (basılmamış). Hacettepe Üniversitesi, Ankara.

Ketel, I.J, Volman, M.N., Seidell J.C., Stehouwer C.D., Twisk JW, Lambalk C.B., (2007). "Superiority of skinfold measurements and waist over waist-to-hip ratio for determination of body fat distribution in a population-based cohort of aucasian Dutch adults". Eur. J. Endocrinol. 156 (6): 655-61.

Kleiber, M. (1975). The Fire of Life. Huntington, NewYork: Robert E. Kreiger Publishing Company,pp. 186-212. 2. 
Koivisto, A. (2009). Weight reduction, body composition, thyroid hormones and basal metabolic rate in elite athletes, Master thesis in Clinical NutritionMedical Faculty, Department of Nutrition,Unıversıty Of Oslo 20th of April, 2009.

Lahti-Koski, M., Pietinen, P., Heliövaara, M., Vartiainen, E. (2002). Associations of Body Mass Index and Obesity with Physical Activity, Food Choices, Alcohol İntake, and Smoking In the 1982-1997 Finrisk Studies. American Journal Of Clinical Nutrition, 75: 809-817

Lofgren, I., Herron, K., Zern, T., Patalay, M., Shachter, N.S., Koo, S.I., Fernandez, M.L. (2004). Waist circumference is a better predictor than body mass index of coronary heart disease risk in ovenveight premenopausal vvomen.The Journal of Nutrition, 134; 1071 -1076.

Milli Eğitim Bakanlığı. (2011). Aile ve Tüketici Hizmetleri, Enerji Hesaplamaları, Ankara.

Mørkedal, B., Romundstad, P.R., Vatten, L.J. (2011). Informativeness of indices of blood pressure, obesity and serum lipids in relation to ischaemic heart disease mortality: the HUNT-II study European Journal of Epidemiology. 26 (6): 457461.

Nazlıcan, E., Demirhindi, H., Akbaba, M. (2011). Adana Illi Solaklı ve Karataş Merkez Sağlık Ocağı Bölgesinde Yaşayan 20-64 Yaş Arası Kadınlarda Obezite Ve İlişkili Risk Faktörlerinin İncelenmesi, Düzce Üniversitesi, Sağlık Bilimleri Enstitüsü Dergisi, 1(2): 5-12

Neyzi, O., Günöz, H., Furman, A., Bundak, R., Gökçay, G., Darendeliler, F., Baş, F. (2008). Türk çocuklarında vücut ağırlığı, boy uzunluğu, baş çevresi ve vücut kitle indeksi referans değerleri. Çocuk Sağığı ve Hastalıkları Derg; 51 (1):1-14.

Noyan, A. (2010). Yaşamda ve Hekimlikte Fizyoloji, Meteksan Yayın, Meteksan.

Pekcan, G. (2000). Şişmanlığın tanımı ve saptanması. III. uluslararası beslenme ve Diyetetik kongresi, s. 93 - 104. Ankara.

Pekcan, G. (2008). Diyet El Kitabı. Ayşe Baysal (Ed.), Beslenme durumunun Saptanması içinde (s. 67- 141). Ankara: Hatiboğlu.

Picon, P.X., Leitão, C.B., Gerchman, F., Azevedo, M.J., Silveiro, S.P., Gross, J.L., Canani, L.H. (2007). "[Waist measure and waist-to-hip ratio and identification of clinical conditions of cardiovascular risk: multicentric study in type 2 diabetes mellitus patients]". Arq Bras Endocrinol Metabol (in Portuguese). 51 (3): 443-9. 
Roubenoff, R., Wilson, P.W. (1993). Advantage of knee height över height as an index of stature in expression of body composition in adults. American Journal of Clinical Nutrition, 57; 609-613.

Sansoy, V. (2001). Body Mass Index, Waist Circumference and Waist Hip Ratios. In Turkish Adults. Editor: Onat A. TEKHARF Yüzyıl Dönümünde Türk Erişkinlerinde Koroner Risk Haritası ve Koroner Kalp Hastalığı, 1.Baskı. İstanbul: Argos Matbaacılık; 2001. p.68-73.

Sharma, A.M. (2003). Obesity and Cardiovascular Risk. Growth Horm Igf Res.;13 Suppl:S10

Temur, H. B. (2018). Bazal metabolizma hizinin seçilmiş değişkenlere göre değerlendirilmesi. Journal of Human Sciences, 15(4), 1914-1923.

Valsamakis, G., Chetty, R., Anwar, A., Banerjee, A.K., Barnett, A., Kumar, S. (2004). Association of Simple Anthropometric Measures of Obesity with Visceral Fat and the Metabolic Syndrome İn Male Caucasian and Indoasian Subjects. Diabet. Med., 21, 1339-1345.

Yardımcı, H., Özfer Özçelik, A., (2006). Ankara İli Gölbaşı İlçesinde Yetişkin Kadınların Antropometrik Ölçümleri Ve Beslenme Alışkanlıkları Üzerinde Bir Araştırma. Ankara Üniversitesi Ev Ekonomisi Yüksekokulu. Ankara.

Yosmaoğlu, H.B, Baltacı, G., Derman, O. (2010). Obez adölesanlarda vücut yağı ölçüm Yöntemlerinin etkinliği. Fizyoterapi Rehabilitasyon, 21(3):125-31. 83

Wikipedi: https://en.wikipedia.org/wiki/Waist\%E2\%80\%93hip_ratio. Erişim tarihi: 17.06.2020

World Health Organization. (2005). Nutrition in adolescence: issues and challenges for the Health sector: issues in adolescent health and development. Geneva: World Health Organization. http://apps.who.int/iris/bitstream/10665/ 43342/1/9241593660_eng.pdf Erişim tarihi: 17.06.2020 